\title{
AKADEEMILISTE VÄLJENDITE VARAMU - KEELERESSURSS, MIS ON ABIKS KIRJUTAMA ÕPPIMISEL JA ÕPETAMISEL
}

\author{
ANNI JÜRINE
}

Annotatsioon. Akadeemiliste väljendite varamu on veebis vabalt kättesaadav uus keeleressurss, mis toetab eestikeelsete akadeemiliste tekstide loomist. Varamu, mis põhineb 200 eestikeelse bakalaureuse- ja magistritöö empiirilisel analüüsil, sisaldab u 750 lõputöödes sagedasti esinevat väljendit, mis on esitatud funktsioonide kaupa. Varamu on mõeldud kasutamiseks eestikeelsete lõputööde kirjutamisel ning aitab üliõpilastel valida akadeemilise teksti jaoks sobiva stiili ja asjakohased retoorilised vahendid. Artiklis antaksegi ülevaade varamu ülesehitusest, koostamise metoodikast ja teoreetilistest alustest ning esitatakse soovitusi varamu kasutamiseks.

Võtmesõnad: akadeemiline väljendusoskus, žanrianalüüs, sõnakimbud, korpuslingvistika, eesti keel

\section{Sissejuhatus}

Oskus koostada selgeid, žanrikohaseid ja sobiva stiiliga tekste on vajalik kõigis haridusastmetes. Enim vajatakse kirjutamisel tuge just kõrgkooliõpingute ajal, kuna ülikoolis nõutavate kirjalike tekstide loomine seab õppijatele nende senise kogemusega võrreldes täiesti uued nõudmised. Uuringud (nt Anson 2016) on näidanud, et oskus kirjutada ühes žanris ei laiene tingimata teistele žanridele. Seega, oskus kirjutada koolitekste (nt kirjandit) ei aita õppijat kõrgkoolis nõutavate tekstide (nt akadeemilise essee või bakalaureusetöö) kirjutamisel. Siinses ülevaates tutvustatakse akadeemiliste väljendite varamut - keeleressurssi, mis toetab akadeemiliste tekstide kirjutamist, aidates autoril leida uurimistöösse sobivad väljendid ja retoorilised vahendid. 
Akadeemiliste väljendite varamu on vabalt kasutatav keeleressurss (teadustekst.ut.ee), mis sisaldab üle 750 eestikeelsetes akadeemilistes tekstides esineva väljendi. Varamusse koondatud väljendid ei ole seotud konkreetse erialaga, vaid on iseloomulikud akadeemilisele registrile tervikuna. Varamus on väljendid esitatud funktsioonide kaupa (nt eesmärgi esitamine, meetodi kirjeldamine, varasema uurimistöö tutvustamine, järelduste tegemine), mis omakorda on seostatud uurimistöö jaotisega (sissejuhatus, sisuosa, kokkuvõte), kus mingi funktsioon tüüpiliselt esineb.

Varamu on koostatud eestikeelsete bakalaureuse- ja magistritööde põhjal ning on esimene akadeemilise eesti keele ressurss, mis põhineb suuremahulisel empiirilisel materjalil. Empiiriline uurimistöö on vajalik, et tuvastada just eestikeelsetes akadeemilistes tekstides esinevad väljendid. Kuna üliõpilastööde tase on kõikuv ja kõik lõputööde sõnastusvalikud ei ole õnnestunud, kasutatakse varamu koostamisel kahesugust lähenemisviisi. Esmalt analüüsitakse materjali deskriptiivselt, et selgitada välja sagedased väljendid ja nende funktsioonid. Seejärel lähenetakse materjalile preskriptiivselt, jättes varamust välja ebaõnnestunud sõnastusvariandid.

Akadeemiliste väljendite varamu on mõeldud abiks eelkõige bakalaureuse- ja magistritööde, kuid ka teistes akadeemilistes žanrides kirjutamisel. Kuna uuringutest on ilmnenud, et akadeemiliste tekstide kirjutamisel, sh sõnastamisel, vajavad abi nii L1 kui ka L2 keelekasutajad (Davis, Morley 2015), on varamu tarvilik nii eesti keeles emakeelena kui ka võõrkeelena kirjutajale.

\section{Teoreetiline taust}

Akadeemiline diskursus koosneb enamjaolt vormelitest (Biber jt 2000: 994), s.o akadeemilistele tekstidele tüüpilistest väljenditest, mis korduvad artiklist artiklisse ja lõputööst lõputöösse. Selliseid väljendeid on kirjanduses nimetatud ka konventsionaliseerunud mitmesõnalisteks üksusteks (conventionalized multi-word units, Morley s.a.) või sõnakimpudeks (lexical bundles, vt nt Biber, Barbieri 2007; Hyland 2008; Cortes 2013). Biber jt (2000: 990-91) defineerivad sõnakimbu sagedase mitmesõnalise järjendi ehk kollokatsioonina, mis koosneb vähemalt kolmest ortograafilisest sõnast. Seejuures ei pea sõnakimp olema idiomaatiline üksus, samuti ei ole sõnakimbud tingimata süntaktilised tervikfraasid ega klausid, nt it has been shown that (Cortes 2013) või uurimused on näidanud, et. 
Selliste sõnakimpude kasutamine näitab kuulumist diskursusekogukonda (discourse community) (Swales 1990: 24-27). Kogukonnas käibiva keelekasutuse all ei mõelda ainult konkreetse eriala oskuskeelt. On leitud, et osa mitmesõnalisi väljendeid on kasutusel erialaüleselt (Lancaster 2016: 442). Seega saab üldistavalt rääkida väljenditest, mis on iseloomulikud akadeemilisele registrile tervikuna. Ingliskeelses akadeemilises tekstis on sellised väljendid näiteks the purpose of the present paper is, the paper is organized as follows, little is known about (Cortes 2013), eestikeelses siinse töö eesmärk on, eesmärgist lähtudes sõnastati järgmised uurimisküsimused, siinses peatükis antakse ülevaade. Seejuures on uurimused näidanud, et üliõpilased peavad selliste väljendite kogumeid kasulikuks, kuna need aitavad neil kirjutamisega algust teha ning annavad suurema kindlustunde, et nende keelekasutus on registriga kooskõlas (Davis, Morley 2015; Rapp, Kauf 2018).

Akadeemilises tekstis esinevad väljendid on seotud akadeemilise teksti suhtluseesmärkidega, mida kirjeldatakse teksti retoorilise struktuuri mudelite (move-and-step models) abil. Retoorilise struktuuri mudelites sisalduvad teadusteksti osade retoorilised võtted (vt nt Swales 1990; Cotos jt 2017). Näiteks on leitud, et ingliskeelse teadusartikli sissejuhatuses esineb tüüpiliselt kolm retoorilist võtet: uurimisvaldkonna kirjeldamine, niši väljatoomine ja niši täitmine (Swales 1990: 141). Retooriliste võtete tuvastamiseks kasutatakse tavaliselt spetsiifilist teksti struktuuri analüüsi metoodikat (vt nt Moreno, Swales 2018), mis eeldab seotud teksti analüüsi. Kuna praegusel juhul ei olnud fookuses teksti retooriline struktuur, vaid väljendid, rakendati varamu koostamiseks N-grammidel põhinevat korpusmeetodit. Seetõttu ei kasutata siinses artiklis retoorilise struktuuri kirjeldamiseks ka terminit retooriline võte, vaid preteoreetilist terminit funktsioon.

\section{Varamu koostamise metoodika}

Varamu koostamisel võeti eeskujuks Manchesteri ülikooli ingliskeelsete väljendite varamu ${ }^{1}$ loomise metoodika (Morley s. a.). Töö käigus läbiti neli etappi: korpuse koostamine, korpusepäringud, väljendite seostamine funktsiooniga ning väljendite sõelumine.

1 http://www.phrasebank.manchester.ac.uk/. 
Korpuse koostamine. Empiirilisel uurimistööl põhineva ressursi loomisel on oluline, et uurimistöö toetuks piisavale materjalihulgale, mis oleks üldkogumi suhtes esinduslik. Suurem materjalihulk vähendab üksikautorite idiolekti mõju lõpptulemusele ning võimaldab kaasata piisaval hulgal eri valdkondade tekste. Et tuvastada eestikeelsetes lõputöödes kasutatav väljendivara, koostati 200 bakalaureuse- ja magistritööst koosnev korpus (umbes 2,2 mln tekstisõna) ${ }^{2}$. Valimisse kaasatud lõputööd on võetud Tartu Ülikooli digihoidlast D-Space ${ }^{3}$, kus tööd on liigitatud Tartu Ülikooli nelja valdkonna - humaniora, socialia, medicina ja realia et naturalia - alusel. Iga valdkonna 2013.-2017. aastal kaitstud lõputööde seast valiti juhuslikkuse alusel 50 eestikeelset tööd.

Korpusepäringud. See etapp koosnes kahest osast: otsisõnade loendi koostamisest ja otsingute tegemisest. Otsisõnade loend koostati N-grammide tuvastamise meetodiga, mida on sarnastel eesmärkidel kasutanud ka Viviana Cortes (2013). N-grammid leiti korpusetööriista AntConc (Anthony 2018) abil. Otsiti 3-, 4-, 5-, 6- ja 7-sõnalisi N-gramme, mis esineksid korpuses vähemalt kümme korda ja vähemalt kümnes töös. Peale asjakohatute tulemuste eemaldamist jäi lõplikku loendisse $382 \mathrm{~N}$-grammi, millest 330 olid 3-grammid ja 52 4-grammid. Kuna väljendeid saab analüüsida vaid konteksti toel, tehti kõikide N-grammide kohta korpusepäring. Otsiti ainult täpseid fraase, otsinguakna suuruseks määrati 500 tähemärki. Pärast korduste eemaldamist jäi lõplikku valimisse 10417 tekstikatkendit.

Väljendite sõelumine. Väljendite sõelumine on protsess, kus ülal kirjeldatud meetodiga leitud tekstikatkendist eemaldatakse kogu teemaspetsiifiline info ning autori originaalne sõnastus. Toetudes Morley (s. a.) metoodikale, eemaldatakse selles etapis terminid ja kõik spetsiifilise tähendusega täistähenduslikud sõnad ning jäetakse alles vaid kollokatsioonilised üksused ja/või vormelid. Näites 1 toodud lausest jäi pärast seesugust sõelumist järele näites 2 esitatud väljend.

(1) Käesoleva magistritöö eesmärgiks oli hinnata 4-kuulise füsioteraapia programmi ja toitumise jälgimise mõju 8-9-aastaste ülekaaluliste laste keha koostisele ning kehalise võimekuse näitajatele. [PB-01747]

(2) siinse magistritöö eesmärk oli hinnata \{mis aja jooksul rakendatud\} \{mille\} mõju \{kellele\}

\footnotetext{
2 Autor tänab Peeter Tinitsat korpuse koostamisel osutatud abi eest.

3 http://dspace.ut.ee/.
} 
Näitest ilmneb, et peale lausekonteksti eemaldamise on väljendeid ka toimetatud. Kuigi oma tööle viitamisel on sõna käesolev äärmiselt sage, peavad keelehooldeallikad (vt nt Eesti Keele Instituudi nõuanne „Käesolev ${ }^{64}$ ) seda tihti liigseks ning soovitavad sõna ära jätta või asendada sõnaga see või siinne. Samuti on soovitatav vältida liigset translatiivi kasutust ${ }^{5}$, mistõttu on vormist eesmärgiks saanud eesmärk.

Väljendite seostamine funktsiooniga. Selles etapis vaadeldi väljendeid kontekstis ning määrati väljendi funktsioon, s.o otsustati, millist akadeemilise teksti funktsiooni (nt teema nimetamine, töö eesmärgi esitamine) iga konkreetne väljend esindab. Funktsioonide määramisel ei järgitud otseselt ühtegi olemasolevat mudelit. Väljend seostati funktsiooniga induktiivselt, tõlgendades väljendi kasutuseesmärki kontekstis. Mõne väljendi puhul on funktsioon selge juba N-grammi põhjal ning laiemat konteksti pole funktsiooni määramiseks tarviski. Näiteks kannab ülal lauses 2 toodud väljend funktsiooni eesmärgi esitamine. Alati aga väljend funktsiooniga seostuvat märksõna ei sisalda. Nii ei pruugi näiteks teema esitamiseks kasutatav väljend sisaldada sõna teema (näide 3). Sellisel juhul eeldab funktsiooni määramine suuremat interpretatsiooni ja laiema konteksti uurimist.

(3) siinne magistritöö keskendub \{millele\}

\section{Akadeemiliste väljendite varamu}

Akadeemiliste väljendite varamu koosneb u 750st akadeemilisele tekstile tüüpilisest väljendist, mis on esitatud töö osade kaupa, kus need tüüpiliselt esinevad (sissejuhatus, töö sisuosa ja kokkuvõte). Varamu ei sisalda väljendite sageduse arvandmeid. Iga tekstiosa kohta esitatakse selles esinevad väljendid, mis on rühmitatud funktsiooni alusel. Peale selle on esitatud ka väljendid, mida kasutatakse selliste funktsioonide väljendamiseks, mis ei seostu otseselt ühegi kindla töö osaga (nt olulisusele osutamine, möönduse väljendamine, tekstiosale viitamine). Tabel 1 annab ülevaate varamus esinevatest funktsioonidest, mida on illustreeritud näidetega.

\footnotetext{
4 http://keeleabi.eki.ee/index.php?leht=8\&id=39.

5 http://keeleabi.eki.ee/?leht=8\&id=227.
} 
Tabel. Varamus esinevad funktsioonid ja väljendite näited

\begin{tabular}{|c|c|c|}
\hline $\begin{array}{l}\text { Töö } \\
\text { osa }\end{array}$ & Funktsioon & Väljend \\
\hline \multirow{7}{*}{ 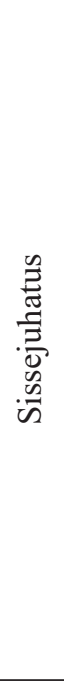 } & Teema nimetamine & $\begin{array}{l}\text { siinses töös on tähelepanu all \{mis } \\
\text { teema\} }\end{array}$ \\
\hline & Teema aktuaalsuse näitamine & $\begin{array}{l}\{\text { kelle }\} \text { seas on oluline uurida ka } \\
\{\text { mille\} arengut, kuna ... }\end{array}$ \\
\hline & Niši väljatoomine & $\begin{array}{l}\text { siinse töö autori arvates on \{mis } \\
\text { nähtus\} seni vähe käsitlemist } \\
\text { leidnud }\end{array}$ \\
\hline & Eesmärgi esitamine & $\begin{array}{l}\text { töö eesmärk on välja selgitada } \\
\text { \{mille\} ja \{mille\} vahelised seosed }\end{array}$ \\
\hline & Uurimisküsimuste esitamine & $\begin{array}{l}\text { siinses töös otsitakse vastust } \\
\text { järgmistele küsimustele }\end{array}$ \\
\hline & Hüpoteesi(de) püstitamine & $\begin{array}{l}\text { sellest lähtudes on püstitatud } \\
\text { hüpotees, et ... }\end{array}$ \\
\hline & Töö ülesehituse tutvustamine & $\begin{array}{l}\text { töö koosneb kahest osast: } \\
\text { teoreetilisest ja empiirilisest }\end{array}$ \\
\hline \multirow{8}{*}{ 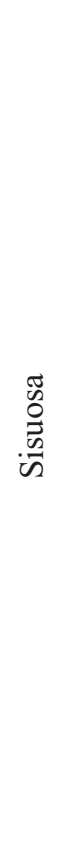 } & $\begin{array}{l}\text { Varasemale uurimistööle } \\
\text { viitamine - kirjeldamine }\end{array}$ & $\begin{array}{l}\text { samasugust metoodikat kasutati } \\
\text { ka \{autori\} et al. \{aasta\} uuringus, } \\
\text { mis ... }\end{array}$ \\
\hline & $\begin{array}{l}\text { Varasemale uurimistööle } \\
\text { viitamine - eesmärk }\end{array}$ & $\begin{array}{l}\text { \{autori\} et al. \{aasta\} uuringu } \\
\text { eesmärk oli hinnata \{mille\} mõju } \\
\text { \{kellele\} }\end{array}$ \\
\hline & $\begin{array}{l}\text { Varasemale uurimistööle } \\
\text { viitamine - tulemused }\end{array}$ & $\begin{array}{l}\text { mitmes uuringus }\{\text { autor ja autor }\} \\
\{\text { aasta }\{\{\text { autor }\} \text { et al. }\{\text { aasta }\} \text { on } \\
\text { selgunud, et ... }\end{array}$ \\
\hline & $\begin{array}{l}\text { Varasemale uurimistööle } \\
\text { viitamine - autoripõhine }\end{array}$ & $\begin{array}{l}\text { Folklorist }\{\text { eesnimi }+ \text { perenimi }\} \text { on } \\
\text { kirjutanud, et ... }\end{array}$ \\
\hline & $\begin{array}{l}\text { Varasemale uurimistööle } \\
\text { viitamine - väitepõhine }\end{array}$ & $\begin{array}{l}\text { mõni aasta hilisemas uurimistöös on } \\
\text { märgitud, et ... }\end{array}$ \\
\hline & $\begin{array}{l}\text { Varasemale uurimistööle } \\
\text { viitamine - tõendamine }\end{array}$ & $\begin{array}{l}\text { Seda tõendab ka \{autori\} \{aasta\} } \\
\text { uuring, kus ... }\end{array}$ \\
\hline & $\begin{array}{l}\text { Varasemale uurimistööle } \\
\text { viitamine - süntees }\end{array}$ & $\begin{array}{l}\text { nende uurimuste põhjal võib } \\
\text { järeldada, et ... }\end{array}$ \\
\hline & $\begin{array}{l}\text { Varasemale uurimistööle } \\
\text { viitamine - kriitika }\end{array}$ & $\begin{array}{l}\text { autori arvates on seesugune } \\
\text { tõlgendus ebaõige, sest ... }\end{array}$ \\
\hline
\end{tabular}




\begin{tabular}{|c|c|c|}
\hline & $\begin{array}{l}\text { Varasemale uurimistööle } \\
\text { viitamine - nõustumine }\end{array}$ & $\begin{array}{l}\text { nagu on välja toonud \{autor\}} \\
\{\text { aasta\}, leiab ka siinse töö autor, } \\
\text { et ... }\end{array}$ \\
\hline & $\begin{array}{l}\text { Meetodi kirjeldus - } \\
\text { meetodi rakendamise eesmärk }\end{array}$ & $\begin{array}{l}\text { selleks et saada ülevaade \{mille\} } \\
\text { olemusest, rakendati \{mis\} meetodit }\end{array}$ \\
\hline & $\begin{array}{l}\text { Meetodi kirjeldus - } \\
\text { andmete kirjeldamine }\end{array}$ & $\begin{array}{l}\text { töö on koostatud \{mis\} võrgustiku } \\
\text { kogutud andmete põhjal }\end{array}$ \\
\hline & $\begin{array}{l}\text { Meetodi kirjeldus - } \\
\text { valimi kirjeldamine }\end{array}$ & $\begin{array}{l}\text { katserühma valimi moodustasid } \\
47 \text { last (30 tüdrukut ja } 17 \text { poissi) }\end{array}$ \\
\hline & $\begin{array}{l}\text { Meetodi kirjeldus - } \\
\text { andmeanalüüs }\end{array}$ & $\begin{array}{l}\text { andmete statistiliseks analüüsiks } \\
\text { kasutati programme \{mis\} ja }\{\text { mis\} }\end{array}$ \\
\hline & $\begin{array}{l}\text { Meetodi kirjeldus - } \\
\text { mõõtevahend }\end{array}$ & $\begin{array}{l}\text { \{mille\} hindamiseks kasutati } \\
\text { \{autori\} et al. \{aasta\} välja töötatud } \\
\text { vaatlusvormi }\end{array}$ \\
\hline & $\begin{array}{l}\text { Meetodi kirjeldus - } \\
\text { kriitika }\end{array}$ & $\begin{array}{l}\text { selle meetodi puuduseks on asjaolu, } \\
\text { et ... }\end{array}$ \\
\hline$\ddot{\mathscr{D}}$ & $\begin{array}{l}\text { Meetodi kirjeldus - } \\
\text { metodoloogiline valik }\end{array}$ & $\begin{array}{l}\text { et hinnata \{mille\} määramisel } \\
\text { tekkivat süstemaatilist viga, kasutati } \\
\text { siinses töös \{mida\} }\end{array}$ \\
\hline$\stackrel{\vec{n}}{\infty}$ & $\begin{array}{l}\text { Meetodi kirjeldus - } \\
\text { pilootuuring }\end{array}$ & $\begin{array}{l}\begin{array}{l}\text { eelkatse oli vajalik selleks, et teha } \\
\text { kindlaks ... }\end{array} \\
\end{array}$ \\
\hline & $\begin{array}{l}\text { Meetodi kirjeldus - } \\
\text { protseduur }\end{array}$ & $\begin{array}{l}\text { enne sekkumist juhendas töö autor } \\
\text { vaatlusalust \{milles\} }\end{array}$ \\
\hline & Infograafikale viitamine & $\begin{array}{l}\text { joonisel } N \text { on esitatud A ja B rühma } \\
\text { erinevused \{milles\} }\end{array}$ \\
\hline & Lisale viitamine & $\begin{array}{l}\text { programmi lähtekood on toodud } \\
\text { lisas } N\end{array}$ \\
\hline & Tulemuste esitamine & uuringu tulemused näitasid, et ... \\
\hline & $\begin{array}{l}\text { Tulemuste esitamine - } \\
\text { seostamine varasema } \\
\text { uurimistööga }\end{array}$ & $\begin{array}{l}\text { \{mis tulemus\} on kooskõlas }\{\text { autor\} } \\
\{\text { aasta } \text { analüüsi tulemustega, mille } \\
\text { järgi on ... }\end{array}$ \\
\hline & $\begin{array}{l}\text { Tulemuste esitamine - } \\
\text { seletamine }\end{array}$ & $\begin{array}{l}\text { üks võimalikke põhjendusi, miks ..., } \\
\text { võib olla see, et ... }\end{array}$ \\
\hline & $\begin{array}{l}\text { Tulemuste esitamine - } \\
\text { tõlgendamine }\end{array}$ & $\begin{array}{l}\text { katsetulemuste põhjal ei saa väita, } \\
\text { kas \{mis\} mõjutavad \{mida\} }\end{array}$ \\
\hline & $\begin{array}{l}\text { Tulemuste esitamine - } \\
\text { hüpoteeside kontrollimine }\end{array}$ & $\begin{array}{l}\text { eelnevale tuginedes leiab osaliselt } \\
\text { kinnitust ka teine hüpotees, mille } \\
\text { järgi ... }\end{array}$ \\
\hline
\end{tabular}




\begin{tabular}{|c|c|c|}
\hline \multirow{2}{*}{ 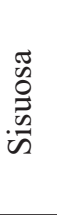 } & $\begin{array}{l}\text { Tulemuste esitamine - } \\
\text { järeldamine }\end{array}$ & $\begin{array}{l}\text { uuringu vältel ei avaldanud \{mis\} } \\
\text { \{millele\} olulist mõju, millest võib } \\
\text { järeldada, et ... }\end{array}$ \\
\hline & $\begin{array}{l}\text { Tulemuste esitamine - } \\
\text { võrdlemine }\end{array}$ & $\begin{array}{l}\text { samuti ei leitud statistiliselt olulisi } \\
\text { seoseid \{mille\} ja \{mille\} vahel }\end{array}$ \\
\hline \multirow{7}{*}{ 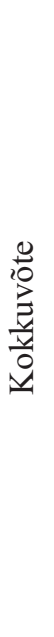 } & Eesmärgi esitamine & $\begin{array}{l}\text { töö põhieesmärk oli välja selgitada, } \\
\text { kas ... }\end{array}$ \\
\hline & $\begin{array}{l}\text { Hüpoteeside kinnitamine/ } \\
\text { ümberlükkamine }\end{array}$ & $\begin{array}{l}\text { seega leidis kinnitust ka hüpotees, } \\
\text { et ... }\end{array}$ \\
\hline & Põhitulemuste esitamine & uurimuse käigus selgus, et ... \\
\hline & Põhijärelduste esitamine & selle tulemuse põhjal järeldati, et ... \\
\hline & $\begin{array}{l}\text { Töö (praktilise) väärtuse } \\
\text { väljendamine }\end{array}$ & $\begin{array}{l}\text { lõputöö tulemusi saab rakendada } \\
\{k u s\}\end{array}$ \\
\hline & Töö piirangute väljatoomine & $\begin{array}{l}\text { tuleb välja tuua töö piiranguid, } \\
\text { millest autori arvates on } \\
\text { olulisimad ... }\end{array}$ \\
\hline & $\begin{array}{l}\text { Edasiste uurimissuundade } \\
\text { väljatoomine }\end{array}$ & $\begin{array}{l}\text { uuringu jätkuna võiks tulevikus } \\
\text { \{mille\} kasutust uurida \{mis\} } \\
\text { meetodiga }\end{array}$ \\
\hline
\end{tabular}

\section{Väljendivaramu kasutamine}

Akadeemiliste väljendite varamu on abivahend uurimistöö kirjutamiseks ja juhendamiseks. Kuigi varamut saab üliõpilane kasutada ka iseseisvalt, on see eelkõige pedagoogiline ressurss, mis mõeldud kasutamiseks üliõpilase ja juhendaja koostöös. Peale väljendite saab juhendaja üliõpilase tähelepanu juhtida ka teksti funktsioonidele ja sellele, kuidas varamus esitatu suhestub struktuuriüksuse lõputöö kirjutamise juhendiga. Sellises juhendamisprotsessis suureneb üliõpilase teadlikkus akadeemilise teksti retoorilisest struktuurist, sh sellest, mis funktsioone väljendid tekstis kannavad ja kuidas keelelised valikud lugejat mõjutavad (Lancaster 2016: 460).

Siinkohal võib tekkida küsimus, kas varamu kasutamine ei piira töö autori loomingulisust ega suru üliõpilasi lõputöö kirjutamisel liiga rangesse raami (vt ka Graff, Birkenstein 2014: 11-12). Loomingulisus on nii uurimis- kui ka kirjutamisprotsessis oluline komponent ning seetõttu tuleb varamu kasutamisel teadvustada, et esitatav väljendite ja funktsioonide 
loetelu ei ole ammendav. Neid väljendeid tuleks võtta kui näiteid akadeemilistes tekstides esinevate funktsioonide väljendamise võimaluste kohta. Niisamuti tasub mõelda sellele, et akadeemilise teksti kirjutamisel ei tohikski üliõpilastelt eeldada liiga suurt loomingulisust. Akadeemiline tekst peab olema küll originaalne oma teadusliku sisu poolest, kuid samas peab see järgima lõputööde žanritunnuseid, sh sisaldama lõputöödele tüüpilisi funktsioone ja võtmefraase, mis aitavad lugejal neid funktsioone ära tunda.

Teine probleem, mis väljendivaramute kasutamisel tekkida võib, on plagiaadikartus. Kuigi väljendivaramu on kokku pandud varem kaitstud lõputööde põhjal ning sisaldab mitmesõnalisi väljendeid, ei ole selle kasutamine plagieerimine. Väljendivaramu alusmaterjalist on väljendite sõelumise käigus eemaldatud originaalne sisu ning alles jäetud ainult keelelised vahendid ehk väljendid. Samamoodi nagu sõnaraamatus esitatud sõnad ja fraasid pole kellegi intellektuaalne omand, ei saa ka varamu sisu käsitleda teiste autorite loominguna. Ka Davis ja Morley (2015), kes on uurinud õppejõudude hoiakuid väljendivaramu kasutamise suhtes, on leidnud, et seesuguste väljendite kasutamist peetakse vastuvõetavaks juhul, kui väljendid on laialt levinud, ei sisalda kellegi arvamust ja on üldised. Eestikeelses akadeemiliste väljendite varamus esitatud väljendid vastavad neile tingimustele.

Varamu koostamise peamine eesmärk on arendada üliõpilaste akadeemiliste tekstide kirjutamise oskust, et muuta nad teadlikumaks lõputöö retoorilisest struktuurist ning lõputööle kohasest keelest ja stiilist. Sellisena on varamu vajalik lisamaterjal lõputööde kirjutamise juhenditele, mis enamasti nii detailseid suuniseid ei anna.

\section{Kirjandus}

Anson, Chris M. 2016. The Pop Warner chronicles: a case study in contextual adaptation and the transfer of writing ability. - College Composition and Communication 67 (4), 518-549.

Anthony, Laurence 2018. AntConc (Version 3.5.7) [Computer Software]. Tokyo: Waseda University. http://www.laurenceanthony.net/ (11.03.2019).

Biber, Douglas, Federica Barbieri 2007. Lexical bundles in university spoken and written registers. - English for Specific Purposes 26 (3), 263-286.

Biber jt 2000 = Douglas Biber, Stig Johansson, Geoffrey Leech, Susan Conrad, Edward Finegan. Longman Grammar of Written and Spoken English. Harlow: Longman. http://dx.doi.org/10.1016/j.esp.2006.08.003. 
Cortes, Viviana 2013. The purpose of this study is to: connecting lexical bundles and moves in research article introductions. - Journal of English for Academic Purposes 12 (1), 33-43. https://doi.org/10.1016/j. jeap.2012.11.002.

Cotos jt 2017 = Elena Cotos, Sarah R. Huffman, Stephanie Link. A move/step model for methods sections: demonstrating rigour and credibility. English for Specific Purposes 46, 90-106. https://doi.org/10.1016/j. esp.2017.01.001.

Davis, Mary, John Morley 2015. Phrasal intertextuality: the responses of academics from different disciplines to students' re-use of phrases. - Journal of Second Language Writing 28, 20-35. https://doi.org/10.1016/j. jslw.2015.02.004.

Graff, Gerald, Cathy Birkenstein 2014. They Say/I Say: The Moves that Matter in Academic Writing. New York, London: WW Norton \& Company.

Hyland, Ken 2008. Academic clusters: text patterning in published and postgraduate writing. - International Journal of Applied Linguistics 18 (1), 41-62. https://doi.org/10.1111/j.1473-4192.2008.00178.x.

Lancaster, Zak 2016. Do academics really write this way? A corpus investigation of moves and templates in "They Say/I Say". - College Composition and Communication 67 (3), 437-464.

Moreno, Ana I., John M. Swales 2018. Strengthening move analysis methodology towards bridging the function-form gap. - English for Specific Purposes 50, 40-63. https://doi.org/10.1016/j.esp.2017.11.006.

Morley, John s. a. Phrasebank: a university-wide online writing resource. https:// tinyurl.com/lgbsxd6 (11.03.2019).

Rapp, Christian, Peter Kauf 2018. Scaling academic writing instruction: evaluation of a scaffolding tool (Thesis Writer). - International Journal of Artificial Intelligence in Education 28 (4), 590-615. https://doi. org/10.1016/j.esp.2017.11.006.

Swales, John 1990. Genre Analysis: English in Academic and Research Settings. Cambridge: Cambridge University Press.

\author{
Anni Jürine \\ eesti ja üldkeeleteaduse instituut \\ Tartu Ülikool \\ Jakobi 2 \\ 51014 Tartu \\ anni.jyrine@ut.ee
}




\title{
Academic phrase bank for writing in Estonian: a language resource to aid in the learning and teaching of writing
}

\author{
ANNI JÜRINE
}

The present paper gives an overview of the Academic Phrase Bank for Writing in Estonian. The phrase bank is a language resource that supports the thesis writing process. The phrase bank is primarily intended to be used as a pedagogical tool during the supervision process, the resource can also be used by students independently.

The phrase bank is a publicly available resource (teadustekst.ut.ee) which includes approximately 750 expressions in Estonian. The expressions are organized according to their function (e.g. stating the aim, indicating a gap, introducing the method, making conclusions, etc.), which are in turn connected to the three major sections in the Estonian thesis (Introduction, Main Body, and Conclusion).

The phrase bank has been compiled based on empirical analysis of Bachelor and Master's theses defended at the University of Tartu in 2013-2017. The semirandom sample consisted of 200 theses, divided equally between the four faculties of the university - Humanities and Arts, Social Sciences, Science and Technology, and Medical Sciences. As such, the phrases in the phrase bank are not associated with any particular field or discipline, but with the academic register in general. All the original content has been removed and the phrase bank only presents academic expressions, such as the aim of the present thesis is to, the remainder of the paper is structured as follows, these results indicate.

The phrase bank is developed for students writing in Estonian as L1 as well as L2, and primarily supports thesis writing at bachelor and master level. This language resource is also useful for users writing in other academic genres, such as essays or research articles.

Keywords: academic writing, genre analysis, lexical bundles, corpus linguistics, Estonian language 